\title{
The Nonlinear Analysis of Steel Tubular Columns Filled with Steel-Reinforced High-Strength Concrete
}

\author{
Xiurong Yang ${ }^{1}$, Li Song*,2,a \\ ${ }^{1}$ Dalian University, China. \\ ${ }^{2}$ Department of civil and architecture engineering, Dalian University, China \\ ayangxiurong6@163.com
}

Keywords: steel tube columns filled with steel-reinforced high-strength concrete; eccentric compression; mechanical property; bearing capacity; regression analysis

Abstract:In order to study the mechanical properties of steel tubular columns filled with steel-reinforced high-strength concrete (STSRHC) under eccentric compression, this paper establishes the formula of bearing capacity, analyzes the effect of eccentricity, slenderness ratio, strength of materials and other factors on the bending column's mechanical properties by the finite element analysis software. Then, we will establish the bearing capacity formula through the regression analysis of data. The results reveal that the calculation results based on software agree well with the experimental data; eccentricity and slenderness ratio have large influence on the mechanical properties of eccentric compression members, strength of materials and shape of steel section have small impact on it; the calculation results based on the formula for the bearing capacity of eccentric compression agree well with the experimental results. The conclusions possess certain instructional significance for the design of new columns.

\section{Introduction}

Steel tubular column filled with steel-reinforced high-strength concrete (In Fig.1) makes full use of the mechanical properties of concrete and steel, it has the advantages of high bearing capacity, high stiffness, good anti-seismic performance and dynamic performance, small sectional size, and so on [1]. This advanced member is expected to be widely used in high-rise buildings, high-rise structure, bridge and underground structure. At present, the exploration still stays in the stage of theoretical study and is still no in practical application.

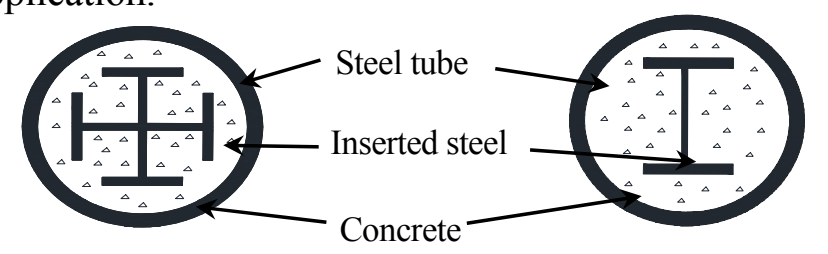

Fig.1 Cross section of STSRHC

To satisfy the need of engineering design, we are ready to study on the mechanical performance of the composite column under eccentric compression by the finite element software. Then, the formula of the bearing capacity of will be put forward in the paper.

\section{Stress-Strain Relational Model}

The constitutive model of core concrete is damaged plasticity model in software, Lianguang Wang model is adopted in the compressive stress-strain curve [2]. Considering the eccentricity effect on the constitutive model of core concrete, eventually a new model is put forward in Eq. 1 for expressing the stress-strain relationship as follows:

$$
\sigma_{c}=\left\{\begin{array}{lr}
f_{c c}\left(2 x-x^{2}\right) & (x \leq 1) \\
f_{c c}\left[1+q\left(x^{a}-1\right)\right] & (\theta \geq 1.12)(x>1) \\
f_{c c} x /\left[\beta(x-1)^{2}+x\right] & (\theta<1.12)(x>1)
\end{array}\right.
$$


In the Eq. $1, x=\varepsilon / \varepsilon_{0} ; \sigma_{\mathrm{c}}$ is the compressive stress of concrete; $f_{\mathrm{cc}}$ is the compressive strength of core concrete; $\beta, q, a$ and other undetermined coefficients associated with the function are shown as follows.

$$
\begin{aligned}
& f_{c c}=\left[1+\left(-0.054 \theta^{2}+0.4 \theta^{\prime}+0.32 \sqrt{\rho}\right)\left(\frac{24}{f_{c}^{\prime}}\right)^{0.45}\right] f_{c}^{\prime} \\
& \varepsilon_{0}=\varepsilon_{c c}+\left[1400+800\left(\frac{f_{c}^{\prime}}{24}-1\right)\right]\left(\theta^{\prime}+0.37 \rho\right)^{0.2} \\
& \theta^{\prime}=k_{e} \theta ; k_{e}= \begin{cases}1-e / r_{c} & \left(e / r_{c} \leq 1.0\right) \\
0 & \left(e / r_{c}>1.0\right)\end{cases} \\
& \varepsilon_{c c}=1300+12.5 f_{c}^{\prime} \\
& \beta=\left(2.36 \times 10^{-5}\right)^{\left[0.25+(\theta-0.5)^{7}+(\rho-0.2)^{5]}\right.} f_{c}^{\prime 2} \times 3.51 \times 10^{-4} \\
& q=\frac{\theta^{0.545}+\rho^{0.3}}{1+\theta^{\prime}+2 \rho} ; \alpha=0.1 \theta^{\prime}-0.3 \rho
\end{aligned}
$$

In the above, $e$ is the eccentricity; $r_{c}$ is the inside radius of steel tube; $f_{c}$-axial compressive strength of concrete, $f_{c}=0.76 f_{c u}-4.5 ; f_{c u}$-cube compressive strength of concrete; $\theta$-stirrup reinforcement ratio, $\theta=f_{t y} A_{t y} / f_{c} A_{c} ; f_{t y}$-yield strength of steel tube; $A_{c}$-area of concrete; $\rho$-confined index of inserted steel, $\rho=f_{s y} A_{s y} / f_{c} A_{c} ; f_{s y}$-yield strength of inserted steel. The models of other materials are shown in Refer.3.

\section{Element Selection And Mesh Generation}

Considering the convergence and accuracy, the three-dimensional solid elements with eight nodes and reduced integral format (C3D8R) are adopted in the loading plate, steel tube, inserted steel and concrete. To enhance the convergence, analysis is performed by the way of refining the mesh.

Once the calculation stopped, the convergence is improved by readjusting mesh density. Mesh generation of each component is shown in Figure 2.

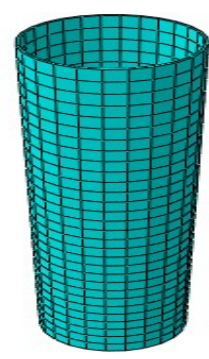

(a) steel tube

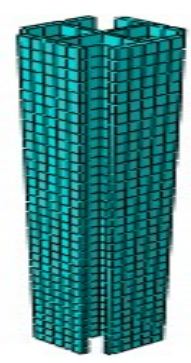

(b) inserted steel

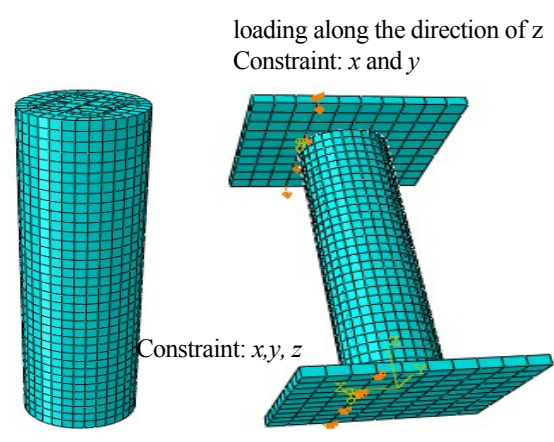

(c) concrete

(d) boundary condition

\section{Comparison Of Simulated Results And Test Results}

Some specimens selected in Refer 3 are used for proving the rationality of the numerical results. And the results of comparison are presented in Fig.3.

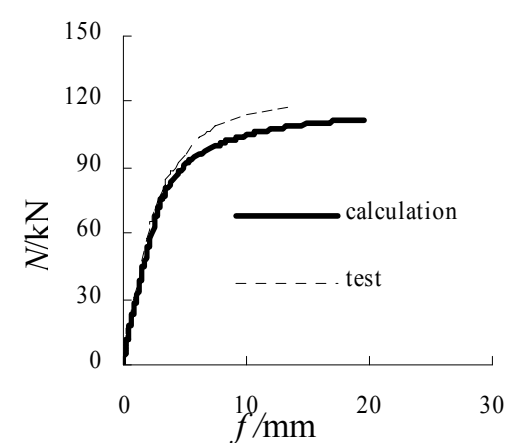

(a) $\mathrm{HC} 10-0$

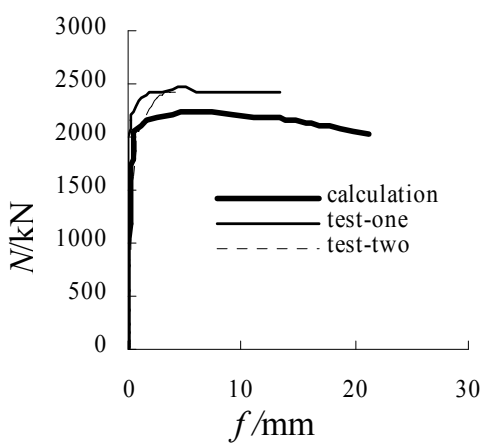

(d) SE-2 


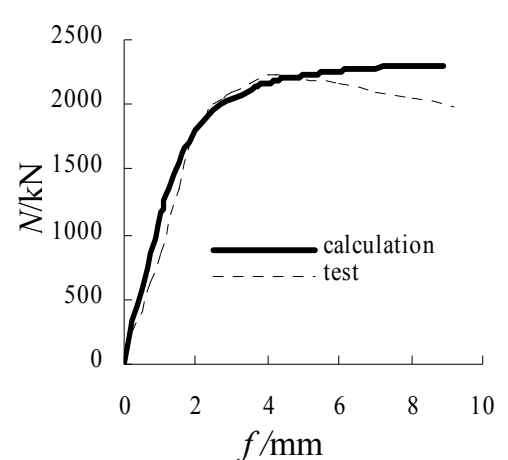

(c) SE-1

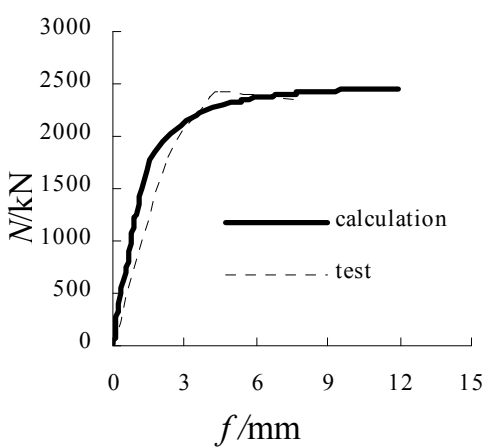

(e) SE-5

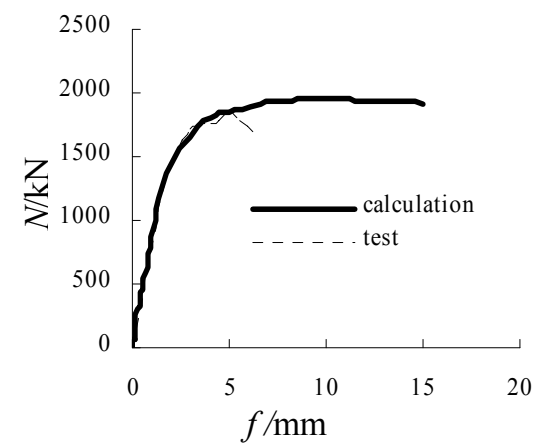

(d) SE-2

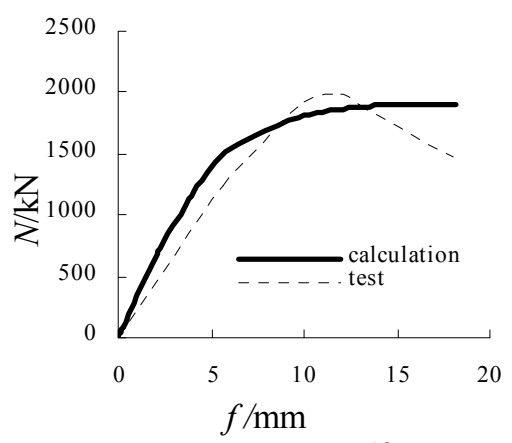

(f) LE-1

Fig.3 Comparison of experimental results and simulated results

In the Fig.3, $\mathrm{D}$ is the diameter of steel tube; $\mathrm{t}$ is the wall thickness of steel tube, $\mathrm{L}$ is the length of column; $\lambda$ is the slenderness ratio, $\lambda=4 \mathrm{~L} / \mathrm{D}$.

The Figure 3 shows that the calculated results agree well with the test results on the whole. The main reason of the errors is that the experimental boundary conditions and the material models hardly fit entirely into this finite element models.

\section{Conclusions}

From the above, it can be concluded:

i) The simulated results are in well agreement with the test results.

ii) Factors influencing on the eccentric mechanical properties are analyzed, we can know the eccentricity and slenderness ratio are the keys to mechanical properties.

iii) The simplified formula of the ultimate bearing capacity is built based on axial force-bending moment correlation method, the calculated results are in well agreement with the test results.

\section{Acknowledgements}

The author would like to thank the financial support by the Liaoning Leading Academic Discipline Project of Liaoning Provincial Education Commission .

\section{References}

[1] Dazhou Zhao. Study on the mechanical properties of axially loaded steel tubular columns filled with steel-reinforced high-strength concrete. PhD Thesis of Dalian University of Technology (2003), p.1-66

[2] Bing Wang, Lianguang Wang, Xiao Liu. Full-Range Analysis of Steel-Reinfoced Concrete Subjected to Concentrically Compression Load[J]. Journal of Shenyang Jianzhu University(Natural Science),2009,25(1):128-132 
[3] Yibin He, Alin Xiao, Jian Guo, etc. Experimental study on behavior of eccentrially loaded steel-reinforced self-compacting high-strength concrete filled steel tubular columns[J]. Journal of Building Structures,2010,31(4):13-20

[4] Linhai Han, in: Concrete filled steel tubular structures-Theory, edited by Science Press Publications, Beijing, China, 2007, in press 